\title{
MAN-MACHINE-ENVIRONMENT SYSTEM ANALYSES AND IMPACT OF ENVIRONMENT FACTORS TO PRODUCTIVITY AND HEALTH OF EMPLOYEES
}

\author{
Ruzena Kralikova, Laura Dzunova, Miriam Pinosova, \\ Emil Wessely, Frantisek Koblasa
}
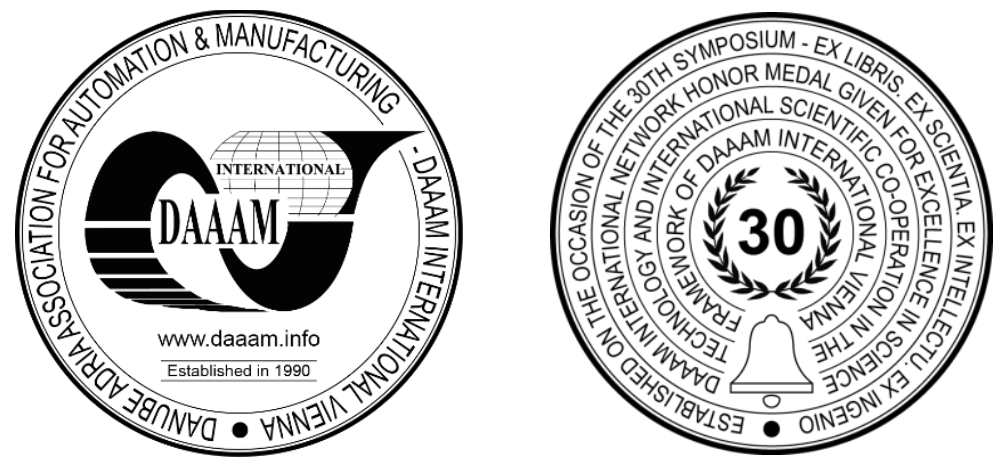

This Publication has to be referred as: Kralikova, R[uzena]; Dzunova, L[aura]; Pinosova, M[iriama]; Wessely, E[mil] \& Koblasa, F[rantisek] (2019). Man-Machine-Environment System Analyses and Impact of Environment Factors to Productivity and Health of Employees, Proceedings of the 30th DAAAM International Symposium, pp.0131-0138, B. Katalinic (Ed.), Published by DAAAM International, ISBN 978-3-902734-22-8, ISSN 1726-9679, Vienna, Austria DOI: $10.2507 / 30$ th.daaam.proceedings.017

\begin{abstract}
In the research literature, the work environment is often characterized by physical, chemical, biological, and cultural complex factors that affect an employee at the workplace. The work environment is part of the "man-machineenvironment" system. In this system, "man" refers to the subject in the workplace (e.g operators, decision-makers), "machine" is the general name for any object controlled by man (tools, machines, computers), and "environment" describes the specific working conditions under which man and machine interact (temperature, noise, vibration, lighting, radiation, chemicals, hazardous gases etc.). The working environment creates a wider or narrower set of factors which are affecting this system. The role of this whole system is to create optimum conditions for achieving the desired results. The three main goals to optimize are to ensure safety, high efficiency, productivity and economy of ,man-machineenvironment" system. Man-machine-environment system engineering is a new developing synthesis frontier science. It analyses three factors for man, machine and environment of the system and the relationship among them to make the system become "safety, and productivity. For problem-solving in this system, the physical factors are very important and may represent a significant risk for employees. These factors affect the human senses, burden the nervous system and can negatively affect overall health and cause stress. Factors can be external (from the environment, psychological, or social situations) or internal (illness). Examination and assessment of working conditions for their impact on employees are challenging, time-consuming and it is essential to do it regularly to achieve reliable results.

This paper relates by comparing the results from previous and current assessments to capture developmental tendency, identify progress or regress and subsequently decide on the next steps.
\end{abstract}

Keywords: Man-Machine-Environment System; Productivity; Health; Comfort.

\section{Introduction}

Humans spend in average $33 \%$ of their lifetime in the workplace. It is safe to say that the job has a huge impact on the quality of life whether positive or negative. Quality of work life is the sense of betterment and happiness at work and the extent to which employees can enhance their personal lives through their work environment and experiences. 
The topic of the negative impact of environmental hazards in the workplace is more and more used in experts discussions as time goes by. Employers can not underestimate this topic and must realize that it is necessary to ensure comfort and safety at the workplace [13].

Creating a clean and healthy work environment with modern technical equipment is very important and it is not a lowcost concern/matter/business for the employer. Many kinds of research, projects and analyzes are focused on this topic due to its importance. The workplace must meet the required conditions which are set out in the legislation. Workplace safety and health protection reduce numbers and possibilities of accidents and health issues of employees and improve business productivity. The creating of a suitable work environment enhances the ability of employees to become more productive. Human to human interactions and relations between a base components of the working environment are playing a more dominant role in the overall job satisfaction are needed for improving the overall performance of the organization in a current era [17].

Physical and mental health, motivation, well training of employees along with workplace conditions reflect on product quality, productivity and performance of employees. About 116 thousand people in Slovakia have a risky job that can have a serious impact on their lives, these people have the highest chance to have workplace accidents and suffer from occupational diseases. An average of 600 employees in Slovakia suffers from occupational diseases per year. Excessive noise, high dustiness and chemical hazards are one of the most common causes of these diseases. Up to 88 thousand people worked in excessively loud conditions in 2015. It is estimated that one-third of European employees (more than 60 million people) are exposed to high levels of noise for more than a quarter-time of their workday [4].

General duty of employers is to ensure the health and safety of employees in all aspects and to carry out risk assessments. The EU Framework Directive emphasizes the crucial importance of risk assessment and sets out the essential provisions for employers.

\section{Work environment quality}

Work environment creates a sense of safety and comfort so it can help to improve employees performance, reduce the occurrence of human errors, work incapacity and occupational diseases. Achieving the right balance to satisfy everybody is not easy.

In modern times, organizations face several challenges due to the dynamic nature of the environment. One of the many challenges for business is to meet the needs of its employees and ensure appropriate working conditions to increase employee efficiency, productivity, and engagement. According to Vroom (1964), job satisfaction is an essential part of motivating and encouraging employees to perform better. Spector (1997) noted that most businesses ignore the working environment within their organization, which adversely affects the performance of their employees. According to him, the working environment consists of employee safety, employment security, good relationships with colleagues, recognition of good performance, motivation for good performance and participation in the company's decision-making process. He further elaborated that when employees realize that they consider their company important, they will have a high level of commitment and sense of ownership for their organization [14].

It is important to realize, that employees are an integral part of the workplace and they help to create a work environment and can change or affect it with their behaviour. The safety and health management systems are essential for business sustainability and the success of the company. Nowadays a strong emphasis is placed on modernization but aesthetics and practicality also should not be forgotten. With the knowledge of many external and internal factors of the work environment that directly affect the performance of the employee, requirements for creating a suitable workplace are increasing. Only employees who are satisfied with the work and social conditions at the workplace can perform highquality work. The level of employee satisfaction, therefore, impacts on the efficiency of their work, but also on their stability. In the context of the improvement of the working environment, it is recommended that the management of companies implement tools for improving and adjusting the work environment with regard to quality. Even such details as the seamless and neat entrance to the building, reception appearance, lift quality and speed, look and equipment of common spaces, amount of parking places, it all creates a corporate image [9]. The first impression of entering the company is very important. Therefore the interior spaces should reflect the purpose the company management wants to achieve. The quality of the work environment is also influenced by several partial aspects such as an image of superiors, co-workers, colleagues, clients, etc., Figure 1.

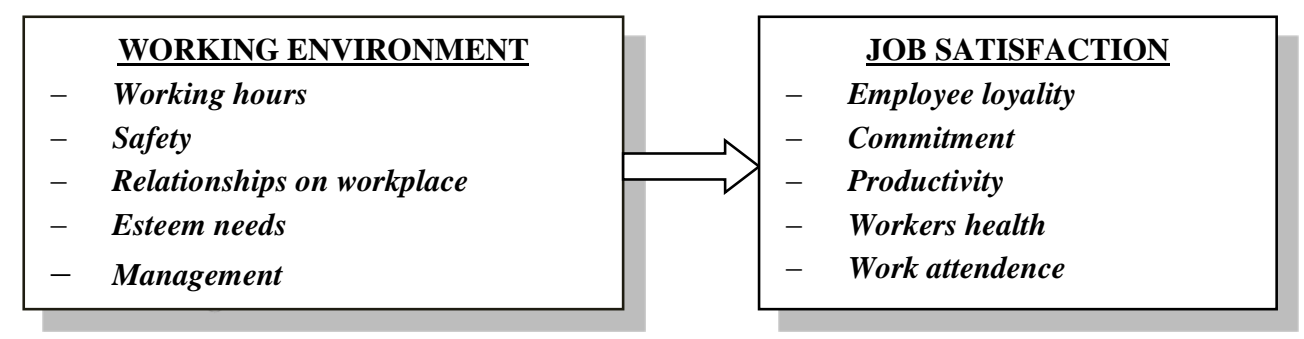

Fig. 1. Work environment factors and job satisfaction 
Creating and obeying work ethics is closely related to the transformation and adaptation of the work environment to provide a sense of safety and comfort. The benefits of providing a good working environment for the employees are tremendous for both the organization and its employees [5].

The perception of the workplace environment is subjective, it depends on an individual's emotional state, his nature, aesthetic feeling and needs. An employee may perceive the work environment positively or negatively and it is important to factor for job satisfaction. According to human resources research, up to $42 \%$ of the interviewees decided to leave their jobs because of unpleasant and unsuitable conditions at the workplace. It is known that most of the people would prefer a comfortable work environment before a higher salary. The clean, comfortable and aesthetic environment is a basic condition for human health and development. Organization and composition of the workplace environment in the last decades has radically changed and this trend will continue. A major challenge will be to reduce monotonous tasks and time pressure because of their negative health impacts. Other stressful factors are fear of job loss, lack of appreciation or bullying. $33 \%$ of male and $22 \%$ of female respondents said their health or safety is at risk due to their job [8].

\section{Man-Machine-Environment System}

The human operator is a powerful, versatile and efficient control element capable of quickly solving unexpected situations and flexibly adapting to different operating conditions. From a safety point of view, the system must be designed in such a way as to avoid serious failures that could cause a health risk, loss of property or environmental damage. Failures can be caused by a machine or by a person who is unable to work and stay alert for an unlimited period of time; therefore, in the latter case, incorrect procedure or wrong decision should be avoided [5]. Information is exchanged at the humanmachine interface in which a person controls or controls a machine called a user interface. The introduction of a user interface in a human-machine system creates a model (Fig. 2.) of a cyclic process in which information is exchanged between man and machine and all this happens in the work environment. In order for this whole process of information exchange to run smoothly, it is necessary to ensure that there is mutual harmony between the elements of the system [2].

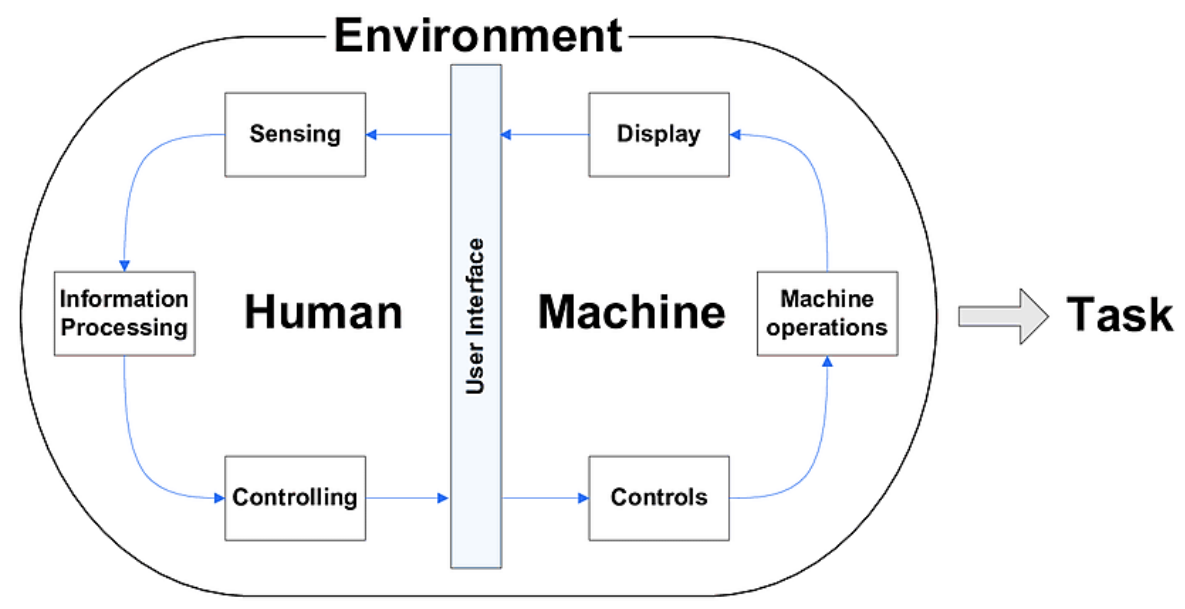

Fig. 2. Work environment factors and job satisfaction [2].

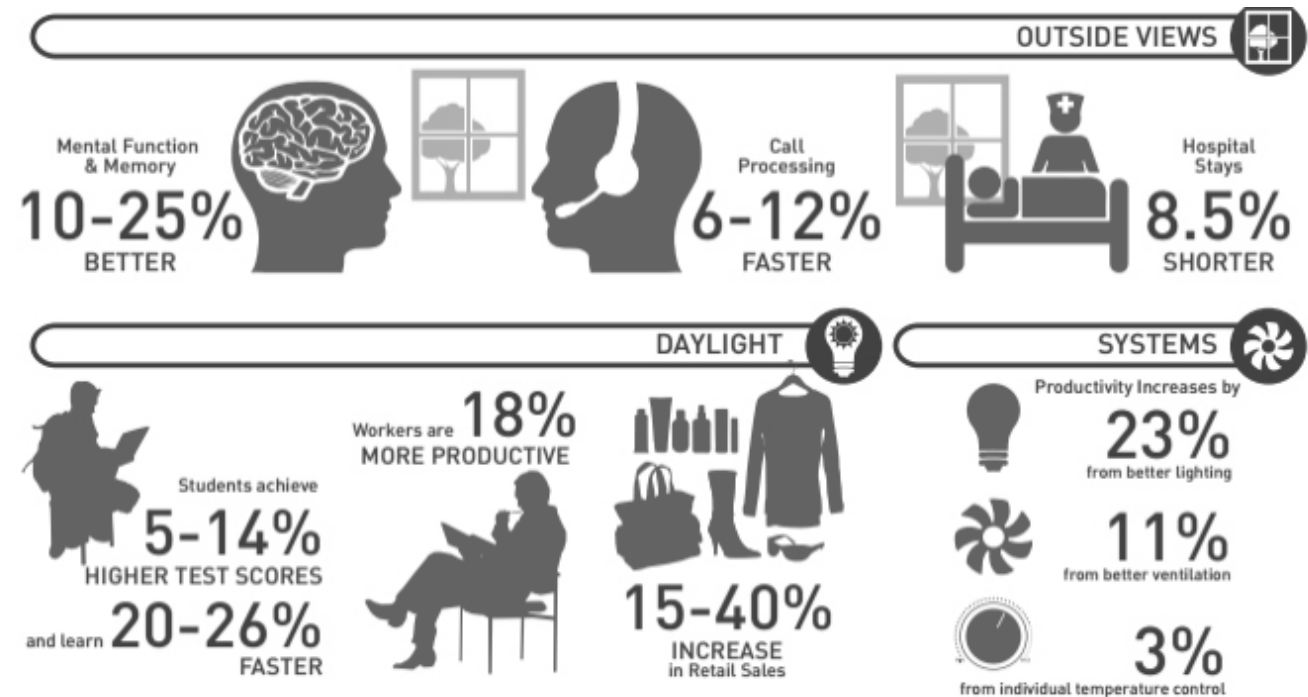

Fig. 3. Measurement criteria for Quality of Life [15] 
Numerous studies link 'green buildings' and labor productivity. Improving labor productivity can have a significant impact on economic growth, given that wages and salaries account for $18 \%$ of total business operating costs and up to $85 \%$ in some service sectors. These improvements are manifested in a number of ways, including reduced absenteeism and improved retention of key employees, consideration is often required at the design stage.

However, retrofitting solutions can also have a significant impact, as an increase in labor productivity of up to $11 \%$ is attributed to improved ventilation and an increase in productivity of $23 \%$ due to improved lighting (Fig. 3.) [15].

The working environment has an impact on a number of important topics in the sustainability agenda, including ethics, employee well-being, employee engagement, and productivity. Table 1 shows the percentage of productivity gains being affected by improvements in the physical factors of the working environment. [3].

\begin{tabular}{|c|c|c|c|c|}
\hline Improved acoustics & $\begin{array}{c}\text { Improved views, } \\
\text { lighting \& daylighting }\end{array}$ & $\begin{array}{c}\text { Improved thermal } \\
\text { comfort \& ventilation }\end{array}$ & $\begin{array}{c}\text { Improved ergonomics } \\
\text { and privacy }\end{array}$ & $\begin{array}{c}\text { Green workplaces vs. } \\
\text { non-green }\end{array}$ \\
\hline $\begin{array}{c}+6 \% \\
\text { productivity }\end{array}$ & $\begin{array}{c}+5.5 \% \\
\text { productivity }\end{array}$ & $+5 \%$ & $+6 \%$ & $+16 \%$ \\
productivity & productivity & productivity \\
\hline
\end{tabular}

Table 1. Measurable productivity gains [3]

Based on research in which indoor environment quality (IEQ) conditions were simulated in 'green' and 'conventional' buildings and assessed for impacts on an objective measure of human performance: higher-order cognitive functions. On various days workers were exposed to IEQ conditions with high, low VOCs concentration or a green building with high outside air ventilation (labelled Green +) and an artificially elevated carbon dioxide (CO2) level independent of ventilation. $101 \%$ higher than the day of conventional buildings ( $\mathrm{p}<0.0001$ ). VOC and CO2 were independently associated with cognitive scores. Cognitive function scores were significantly better in Green + building conditions than in conventional building conditions for all nine functional domains (Fig. 4.). These findings have far-reaching implications because this study was designed to reflect the conditions we normally encounter every day in many indoor environments [1].

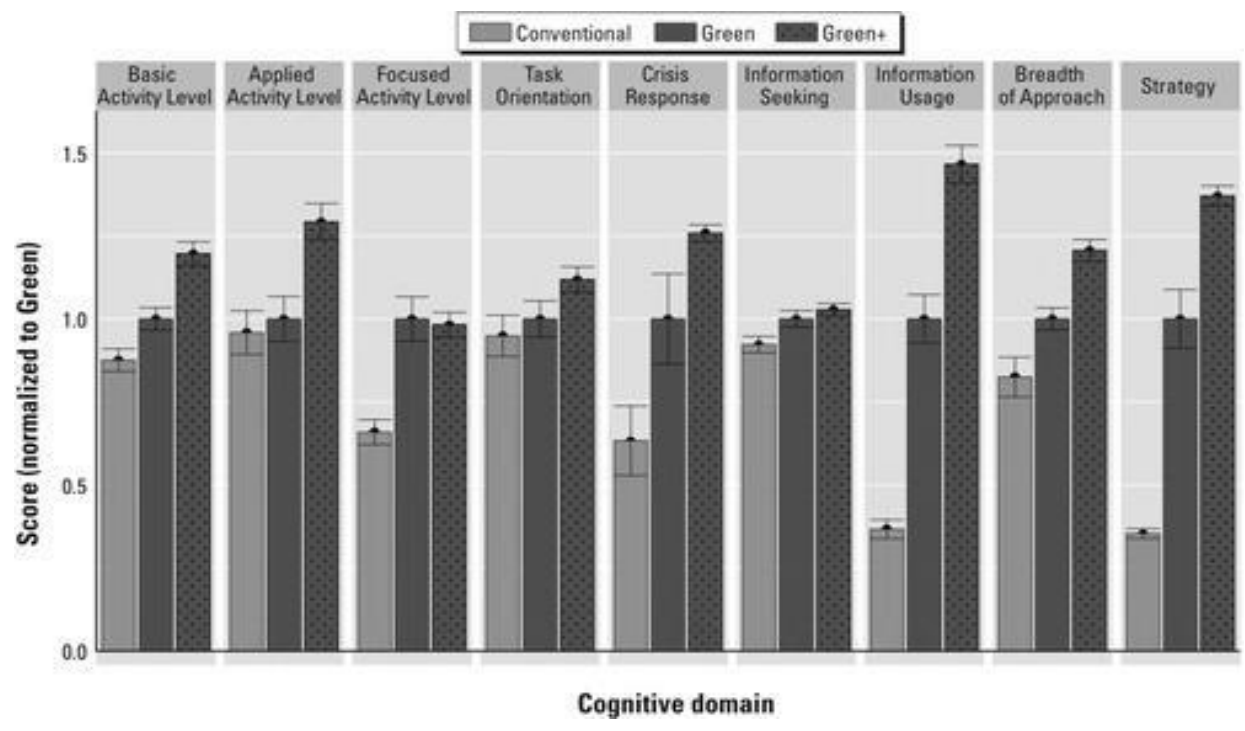

Fig. 4. Workers cognitive functions in buildings with different VOCs concentrations [1]

Taking into account the human-machine-environment system as the basis for establishing the target safety assessment system and for determining the system level of the structure and the target weight of the safety assessment. Man-machineenvironment systems engineering is a new evolving synthesis of frontier science. It analyzes three factors for human, machine and environment and their relationship to make the system "safe, cost-effective and highly efficient".

Deeply analyzing the relationship between man and machine and the environment, we find that the causes of dangerous human behavior are due to many facts, such as the mentality of man., physiology, managerial decisions, social environment, and incompatible human-machine interface design, and so on. The mental aspect of a person mainly concerns temperament, personality, and emotions. The physiological aspect of a human being relates primarily to limitations of human abilities, including human perception, feeling, reaction rate, strength, etc. Management decisions are related to inadequate operating time, operational plans, etc. The causes of the social environment include the physical environment and the human environment or, in other words, whether the workplace and relationships with others are good or not. The reason for the design of the man-machine interface relates in particular to the misallocation of man-machine functions and the inadequate engineering design that can easily lead to mistakes. [19] 
Influence of dangerous human behavior on human-machine-environment safety. Statistical indicators show that for all system failures, approximately $70 \%$ to $90 \%$ are directly or indirectly caused by human error. Human behavior in danger is the most important factor in the failure of the human-machine-environment system, so it is very important to avoid human error in increasing the safety of the human-machine system.

In Industry 4.0, we encounter new types of interactions between operators and machines. Interactions that transform the industrial workforce and will have significant implications for the nature of the work in order to adapt to the everincreasing reliability of production. An important part of this transformation is the focus of people in the factories of the future, which allow a shift from independent automated and human activities to a symbiosis of human-automation (or "human-computer physical systems") characterized by collaborating machines with people they did not replace people's skills and abilities, but rather that they coexist with people and help them to achieve them more efficiently and effectively. Operator 4.0 generation is the "operator of the future", an intelligent and experienced operator who, if necessary, works with machines. It introduces a new design and engineering philosophy for adaptive manufacturing systems that emphasizes automation as a further enhancement of human physical, sensory and cognitive capabilities through the integration of the human cybernetic system (Fig. 5.). [12]

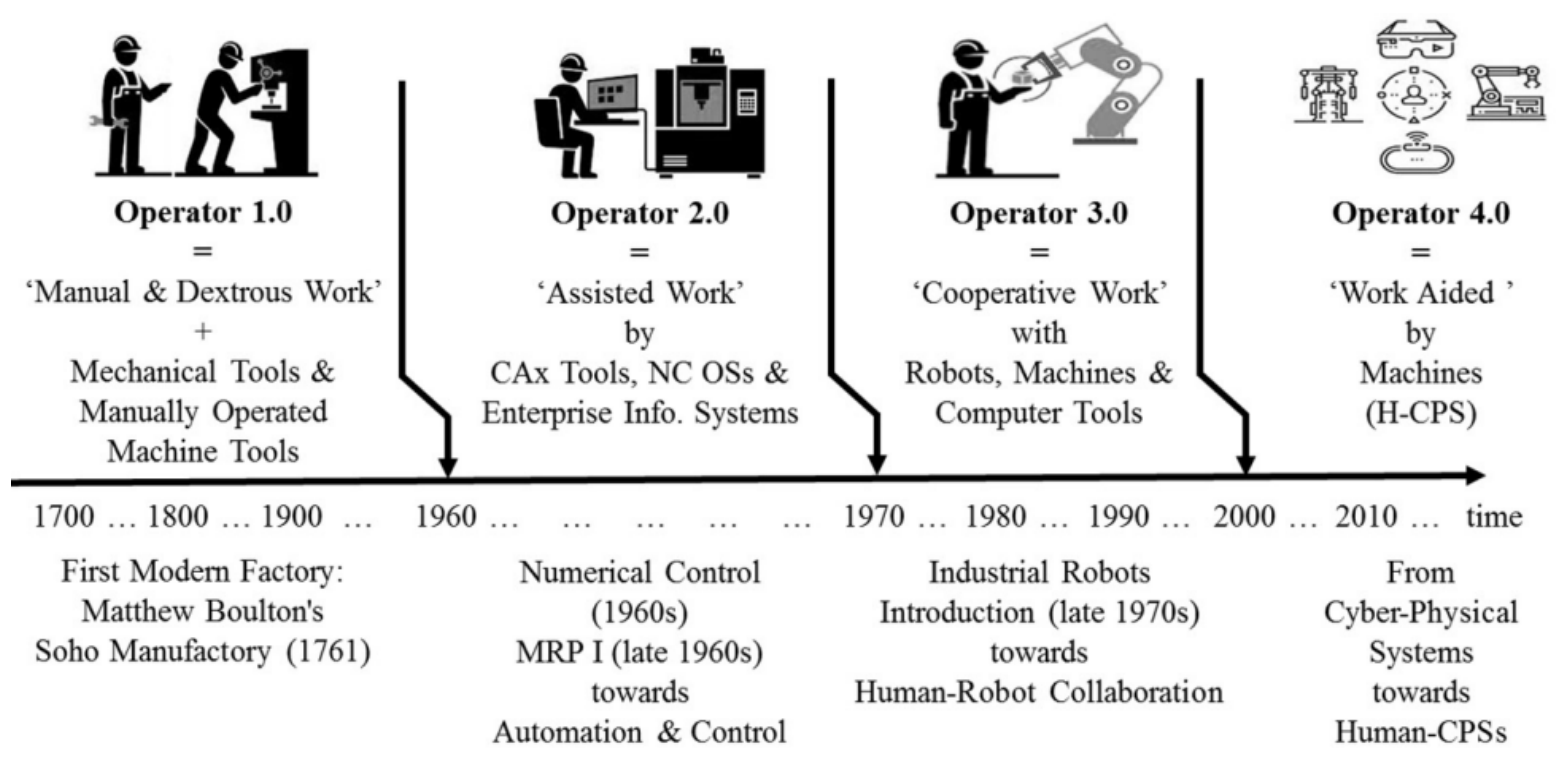

Fig. 5. Operator generations (R)evolution [12]

The Fourth Industrial Revolution marks a new leap in industrial production by bringing together people, machines, and products by creating a new production system that enables faster and more targeted information exchange. This change is moving towards a future where people will work with robots and be supported by web technology and intelligent assistance systems in their work [7]. Industry 4.0 would be inconceivable without a human component. Therefore, the aim of the symbiosis of human-automation through Human Cyber-Physical Systems (Fig. 6.) and AA Adaptive Automation is to create appropriate working conditions.

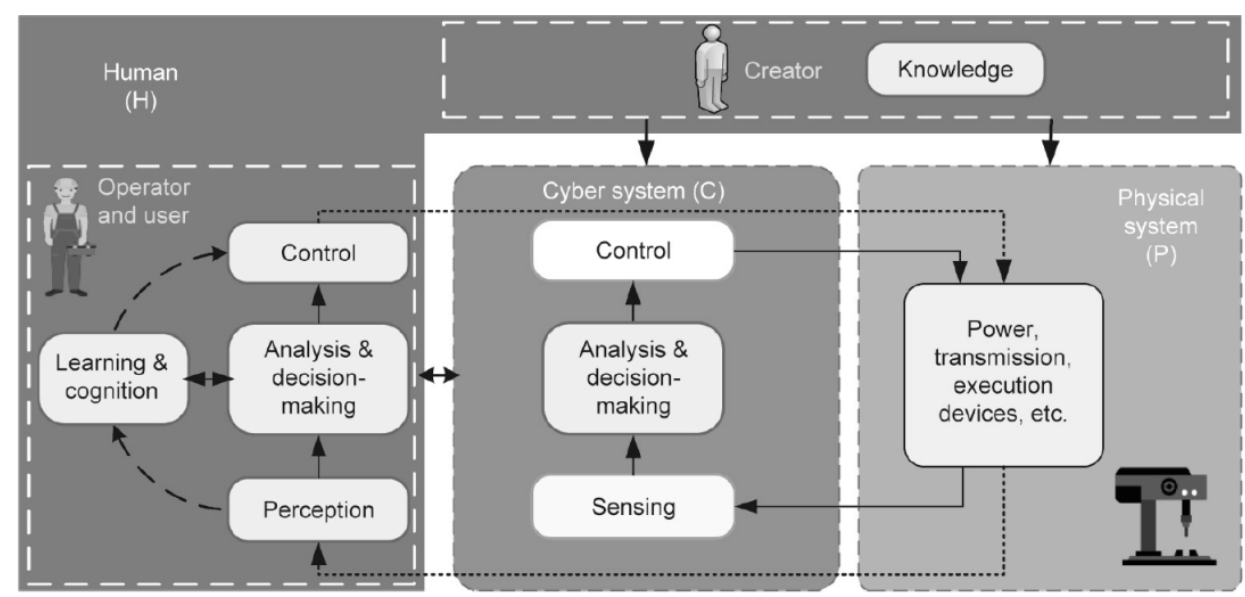

Fig. 6. Operator generations (R)evolution [6] 
Workers are the determinants and machine is a key factor in the human-machine-environment system. So it is important that we thoroughly analyze the relationship between the machine and the accident in order to increase system safety. The workplace environment has a great influence on the habits of workers. A favorable environment can create a pleasant working atmosphere. Poor environment causes physiological, pathological, effective and mental effects of man. It affects the health and efficiency of work and even endangers people's lives. Secondly, environmental factors affect the safety of production. For example, high temperature, high humidity, low pressure, oscillation, noise, dust and some harmful gases other than floods, fire, gas explosion, and various environmental factors are unsatisfactory factors in the working environment [11].

All three parts of the system are equally important and influence each other, and therefore it is necessary to look at them as a whole and pay enough attention to every single one of them. In the literature, the work environment is often characterized as a set of physical, chemical, biological, social and cultural factors that may affect a person at the workplace. Their negative impact depends on their intensity, duration, and frequency. The most frequent factors of the working environment are noise, vibration, lighting, climatic conditions, radiation, gases, and chemicals.

\section{Stress and exhaustion}

Stress is one of the variables that affect operator perception, decision making, and response selection. Many factors including operator's age, training, motivation, etc. affect the success of task performance. Occupational stress and its impact on health and well-being have been the subject of several studies. Long working hours or excessive work and high workload or burnout syndrome have been found to be related to cerebrovascular diseases, the incidence of diabetes and even uncontrolled eating disorders. Work tensions and stress have been found to be related to emotional exhaustion and depersonalization and could affect anxiety and depression or other psychiatric illnesses.

If work and work are unbalanced, there are adverse health effects. The key to work-related stress is to increase the sense of worker control, including the provision of resources, the promotion of self-efficiency and methods of active coping and social support. Work organizational factors, including labor policies, working conditions, people-to-people support, and even workplace management and management, affect workload, stress and the level of worker exhaustion. Lower levels of job control and reduced social support at work are associated with a higher risk of dementia. Lower workload and physical load, high task resources, and good leadership are related to better working ability [10]. Stress is a physical, mental, or emotional factor that causes bodily or mental tension and it can have a negative impact on work performance (Fig. 7.). Job stress and job satisfaction are important factors affecting workforce productivity.

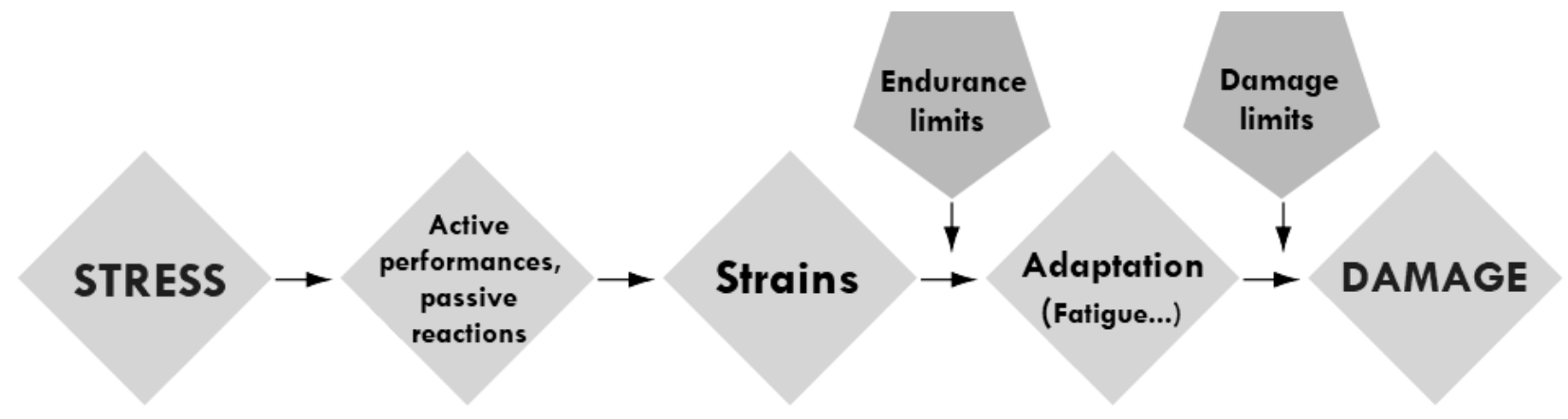

Fig. 7. Stress development

The level of stress is directly proportional to the difficulty of the work task, the negative impact of work environment factors and workplace conditions. The presence of stress leads to the unwanted burden of employee and its intensity depends on concentration, duration, and composition of stress factors. This combined stress can be managed actively or passively, it depends on the behavior and character of the individual. The active case will include activities to improve conditions at the workplace and eliminate causes of stress, while in the passive case stress effects will be managed by natural body response. The ability of stress resistance depends on various factors, for example, employee motivation, concentration, mental and physical health, character traits, etc. [18].

Stress is usually perceived only in a negative light, but stress can also have a positive effect. It can improve performance and can motivate people to do more than otherwise would. These positive hips of stress are reflected e.g. in 
Nixon's research (1979), with a model on performance at stress excitement levels. Relationship between the level of stress and performance depicted in the form of an inverted U-curve (Fig. 8.) [16].

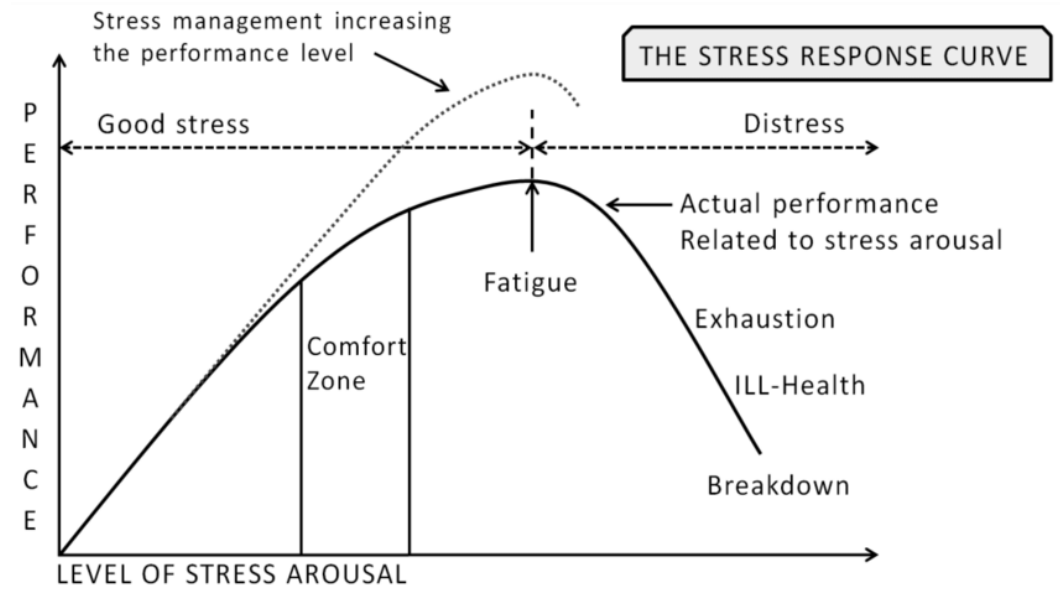

Fig. 8. Stress - performance relation [16]

\section{Conclusion}

Examination and assessment of working conditions from the point of view of their impact on employees are challenging, time-consuming and it is essential to do it regularly (in certain cycles, e.g. annually) in order to achieve reliable results. By comparing the results from previous and current assessments, it is possible to capture developmental tendency, identify progress or regress and subsequently decide on the next steps which will help to ensure continuous improvement, achieve business objectives and customer satisfaction. If the implementations of work environment factors assessment and protection against its negative influence become an enterprise's rule and an integral part of the occupational health and safety management system, it can represent one of the pillars for a successful business. Public opinion surveys may be useful in detecting and eliminating potential work environment risks for employees in different sectors. These surveys also help to understand the differences between opinions and needs of people in a different age, gender, level of education, profession, etc. and to create optimal conditions which will also meet the legislative requirements. The working environment has a positive impact on job satisfaction of employees. Bad working conditions restrict employees to portray their capabilities and reach full potential, so it is imperative that businesses realize the importance of good working environment. This paper could be contributing to the awareness of the importance of a good working environment for job satisfaction. By the optimizing of the working conditions could be improved on the future performance of businesses by taking their work environment more seriously within their organizations to increase the motivation and commitment level of their employees, too.

The future research will oriented to the working conditions in Industry 4, where man work is increasingly transforming from physical work to intellectual work - increasing support for a cognitive and sensory support system for coordination, monitoring, and decision-making processes . The worker who uses her hands to mold a specific of product part will soon do the same thing in an augmented or virtual reality space. The main goal of research will addresses to the question of human labour that could possibly be substituted within the industry 4.0 and impacts on their working environments to ensure that the employees of the organization will have the ease of working in a relaxed and free environment without burden or pressure that would cause their performance to decline. This way the workforce could achieve better results. It will be crucial to develop skills such as creativity, ICT literacy, complex problem solving and critical thinking but also fast learning, listening and adoption on different environments. The benefits of providing a good working environment for the employees are tremendous for both the organization and its employees. There is, therefore, a need for training research that calls on technical colleges, education platforms and companies to prepare for existing as well as to qualify new operators in the factory of the future. Further research is also needed to better understand the effects of sector 4.0 in its practical implementation, especially with regard to stakeholders.

\section{Acknowledgments}

The paper was elaborated within the framework of the projects: KEGA 045TUKE-4/2018 "Transfer of the latest findings of research into processing textbook "Environmental aspectsof design engineering objects -Ecodesign", and KEGA 041TUKE-4/2018 which are solved at Department of process and environmental engineering, Technical University of Kosice and as part of project solved at the Technical University of Liberec- No 21278 „, Optimization of manufacturing systems, 3D technologies and automation“. 


\section{References}

[1] Allen, J.G. MacNaughton, P. Satish, U. Santanam, S. Vallarino, J. \& Spengler, J.D. (2016). Associations of cognitive function scores with carbon dioxide, ventilation, and volatile organic compound exposures in office workers: a controlled exposure study of green and conventional office environments. Environ Health Perspect Vol. 124, No.6 (2016), pp. 805-812. https://doi.org/10.1289/ehp.1510037

[2] Bligard, L-O. (2012). Predicting mismatches in user-artefact interaction - Development of an analytical methodology to support design work.

[3] Curtis, C. (2018) Workplace productivity and ethics: Building Integrity. Available at: https://www.csrwire.com/press_releases/40771-Workplace-Productivity-and-Ethics-Building-Integrity-

[4] European Agency for Safety and Health at Work, European opinion polls on safety and health at work. https://osha.europa.eu/sk/surveys-and-statistics-osh/european-opinion-polls-safety-and-health-work,

[5] Gołębski, R., \& Ivandić, Ž. (2018). Analysis of Modification of Spur Gear Profile. Technical Gazette, 25 (2), $643-$ 648. https://doi.org/10.17559/TV-20171018100732.

[6] Ji, Z. \& Yanhong, Z. \& Wang, B. \& Jiyuan, Z.. (2019). Human-Cyber-Physical Systems (HCPSs) in the Context of New-Generation Intelligent Manufacturing. Engineering. DOI: 10.1016/j.eng.2019.07.015.

[7] Koblasa,F... [et al.] ( 2017).Possibilities of using Kinect sensor in ergonomic. DAAAM 2017. Vienna.: DAAAM, Vol 28 (1) P. 0131-0135. - ISBN 978-3-902734-11-2.

[8] Koblasa, F., Sirova, E. \& Kralikova, R.: The Use of Process Thinking in the Industrial Practice - Preliminary Survey. Technical Gazette. 26 (3). Pages: 786-792. DOI: 10.17559/TV-20150617135306

[9] Kralikova, R. - Rusko, M. - Prochadzkova D. - Wessely, E.(2015) Integrated environmental permitting process in Slovakia / R. Kralikova ... [et al.] - 2015. In: DAAAM International Scientific Book 2015. Vienna : DAAAM International, 2015 P. 359-368. ISSN 1726-9687

[10] Kralikova,R. \& Wessely, E.( 2018)Impact of the environmental factors and its effects on productivity and health / Ružena Proceedings of the 29th DAAAM International Symposium. - Viedeň (Rakúsko) : DAAAM International Vienna s. 119-124 [online]. - ISBN 978-3-902734-20-4

[11] Kremljak, Z. \& Kafol,C. (2013) Types of Riskin a System Engineering Environment and Software Tools for Risk Analysis. Annals of DAAAM and Proceedings of the International DAAAM Symposium. Volume 24, Issue 1, 2013, Pages 177-183. DOI: 10.1016/j.proeng.2014.02.218.

[12] Romero, D. \& Bernus, P. \& Noran, O. \& Stahre, J. \& Fast-Berglund, A. (2016). The Operator 4.0: Human CyberPhysical Systems \& Adaptive Automation Towards Human-Automation Symbiosis Work Systems. DOI: 10.1007/978-3-319-51133-7_80.

[13] Rusko, M., Pavlova, I., Vanova, J. \& Kralikova, R. (2017) Connectivity of quality management systems and environmental management systems. Annals of DAAAM and proceedings of the international DAAAM symposium. pp. 1213-1220. ISSN: 17269679 DOI: $10.2507 / 28$ th.daaam.proceedings. 169 .

[14] Rusko, M. et al.: (2017): The management tools and methods application of the organization to environmental protection. Annals of DAAAM and Proceedings of the International DAAAM SymposiumVolume 27, Issue 1, 2016, Pages 283-288. DOI: 10.2507/27th.daaam.proceedings.042.

[15] Saddler, Anita \& Smith, Michael. (2014). Doubling energy productivity of the built environment by 2030 by Anita Saddler, Mike Smith et al.

[16] Salmela, E. \& Happonen, A. \& Hirvimaki, M. \& Vimm, I.. (2015). Is Time Pressure an Advantage or a Disadvantage for Front End Innovation - Case Digital Jewelry. Vol. 3 (2015 pp.42-69. DOI: 10.24840/21830606_003.004_0005.

[17] Sell, L. - Bryan, C. : Job Satisfaction, Work Environment, and Rewards: Motivational Theory Revisitedlabr. LABOUR, Vol. 25, 1/2011, pp. 1-23.

[18] Tariq, M.; Ramzan, M., \& Riaz, A. (2013). The Impact of Employee Turnover on The Efficiency of The Organization. Interdiciplinary Journal of Contemporary Research in Business , 4(9), pp. 700-711.

[19] Xiaoyan, S. \& Zhongpeng, X. (2014). Application of Man-machine-environment System Engineering in Coal Mines Safety Management. Procedia Engineering. Vol.84, (2014), pp. 87-92. DOI: 10.1016/j.proeng.2014.10.413. 